\title{
Discourse Particles in the Left Periphery
}

\author{
Malte Zimmermann \\ Humboldt Universität Berlin \\ malte.zimmermannestaff.hu-berlin.de
}

\begin{abstract}
This article analyses the German discourse particle wohl 'I suppose', 'presumably' as a syntactic and semantic modifier of the sentence types declarative and interrogative. It is shown that wohl does not contribute to the propositional, i.e. descriptive content of an utterance. Nor does it trigger an implicature. The proposed analysis captures the semantic behaviour of wohl by assuming that it moves to SpecForceP at LF, from where it can modify the sentence type operators in Force ${ }^{0}$ in compositional fashion. Semantically, a modification with wohl results in a weaker commitment to the proposition expressed in declaratives and in a request for a weaker commitment concerning the questioned proposition in interrogatives. Cross-linguistic evidence for a leftperipheral position of wohl (at LF) comes from languages in which the counterpart of wohl occurs in the clausal periphery overtly. Overall, the analysis sheds more light on the semantic properties of the left periphery, in particular of the functional projection ForceP.
\end{abstract}

\section{Introduction}

This paper brings together the old problem of the syntactic, semantic and pragmatic analysis of discourse particles with formal approaches to the syntax and semantics of the left periphery. In particular, the German discourse particle wohl in (1b) is analysed as a modifier on force (or sentence type) operators, such as declarative and interrogative. As such, wohl must be located in the left periphery at LF.

(1) a. Hein ist auf See.

Hein is at sea

'Hein ist at sea.'

b. Hein ist wohl auf See.

Hein is at sea

$=$ Speaker assumes that Hein is at sea

The discussion is to be seen in the context of formal semanticists' renewed interest in discourse particles. These are argued to be special in that they do not contribute to the descriptive, i.e. propositional or truth-functional, content of an utterance, but to its expressive content (see Kratzer 1999 and von Fintel 
2002 for discussion). The present analysis of wohl argues that at least part of the linking between descriptive and expressive content takes place compositionally in the left periphery of the clause, more specifically in the domain of ForceP. The analysis thus sheds more light on the semantic properties of this functional domain that was postulated by Rizzi (1997) on independent syntactic grounds.

The paper is organised as follows: The remainder of this section gives a brief overview of the main characteristics of the discourse particle wohl as found in the literature (see e.g., Abraham 1991; Asbach-Schnitker 1977; Doherty 1979, 1985; Jacobs 1991; Molnár 2001; Weydt 1969). Sections 2 to 4 present a number of observations that are relevant for the analysis. Section 2 shows that the interpretation of wohl is sensitive to sentence types. Section 3 shows that wohl does not form part of the proposition. Section 4 shows that wohl does not trigger conventional implicatures. The syntactic and semantic analysis of the discourse particle wohl is presented in section 5. Section 6 briefly addresses a number of open issues. Section 7 is the conclusion.

\subsection{Surface Syntax}

In surface syntax, wohl occupies positions that are typical for adverbial elements (cf. Jacobs 1991). In (2a), wohl occurs in the middle field at the left edge of VP, preceding all other adverbials. In (2b), it occurs as a DP-internal modifier.

(2) a. dass Hein wohl [vpheute [vphier [vp ein Mädchen getroffen hat]]]. that Hein today here a girl met has '...that Hein seems to have met a girl here today.'

b. der wohl attraktiv-ste Matrose the attractive-superl sailor 'the presumably most attractive sailor.'

The surface-syntactic distribution of wohl indicates that it has not lost its original categorial status as an adverb despite its special semantic status (cf. Molnár 2001). In its original adverbial use, still attested in cases such as (3ab), wohl seems to be cognate to English well.

(3) a. Der König hat wohl geruht. the king has well rested 'The king slept well.'

b. der wohl erzogene Junge the well raised boy 'the boy that was brought up well' 


\subsection{Semantic Contribution: A First Approximation}

As a first approximation, wohl expresses a certain degree of epistemic uncertainty about the proposition of the clause it occurs in. It is used to express hypothetical statements rather than absolute certainties. It follows that an utterance containing wohl is infelicitous in contexts expressing absolute certainty, as shown in (4a). Nor can it be embedded under a verb expressing absolute certainty, as shown in (4b).

(4) a. \#Ich weiß genau, wo Hein ist. Er ist wohl auf See

I know for sure where Hein is he is at sea

\# 'I know for sure where Hein is. Presumably, he is at sea.'

b. *Ich weiß genau, dass Hein wohl auf See ist

I knowfor sure that Hein at sea is

\subsection{Distributional Restrictions}

Another striking fact about wohl is that it is restricted to sentence types that are evaluated at epistemically accessible indices. Such sentences are about what can be known (see Lohnstein 2000). Consequently, wohl is found in declarative and interrogative sentences, as in $(5 \mathrm{a}, \mathrm{b})$. In contrast, it cannot occur in imperative sentences, which are evaluated at factive indices, referring to what is or should be the case, as shown in $(5 \mathrm{c})$.
a. Hania hat wohl auch ihre Chefin eingeladen. declarative Hania has also her boss-fem invited
'Presumably, Hania has invited her boss, too.'
b. Hat Hania wohl auch ihre Chefin eingeladen? interrogative Has Hania also her boss-fem invited
$\approx$ 'What is your guess: Did she or didn't she invite her boss?'
c. *Sei wohl still! be quiet
imperative

The ungrammaticality of $(5 \mathrm{c})$ suggests that wohl operates on another modal base than the modes of imperative clauses, namely on the epistemic base (what can be known). This conclusion is consistent with the observation that wohl expresses epistemic uncertainty from section 1.2.

In the next three sections, I will introduce three more properties of wohl that will come to play a crucial role in the analysis. 


\section{Sentence Type Sensitivity}

Apart from a restriction to certain sentence types, wohl exhibits a second kind of sentence type sensitivity. The 'epistemic reference point' for the evaluation of wohl depends directly on the type of sentence that wohl occurs in. The term 'epistemic reference point' here refers to that discourse participant (speaker, addressee, or both) whose epistemic state or knowledge is under discussion.

First, we find that the epistemic reference point of wohl in declarative clauses is the speaker (cf. Abraham 1991). This means that wohl in declaratives expresses uncertainty on the part of the speaker. We have seen in (4) that wohl is infelicitous in a declarative utterance if the speaker is absolutely certain about the proposition expressed by the utterance. In addition, (6) shows that for licensing wohl in declaratives it is not sufficient that one of the discourse participants (here the addressee A) is uncertain about the proposition under discussion if it is not the speaker.

(6) SPEAKER (B) CERTAIN, ADDRESSEE (A) UNCERTAIN:

A: Where is Hein? I have a suspicion where he is, but I am not sure.

B: \#Ich weiß, wo Hein ist. Er ist wohl auf See.

I know where Hein is he is at sea.

The picture changes with interrogatives. Here, the epistemic reference point of wohl is undetermined as long as it is not the speaker alone. Rather, an interrogative clause containing wohl indicates that the addressee does not know the answer for sure (cf. Asbach-Schnitker 1977). Given this, there are two possible ways to make a question with wohl felicitous. In the first case, both addressee and speaker of the question are uncertain about the answer. This is illustrated in (7a), uttered in a context where speaker and addressee are lost and wonder about the right way out. In the second case, only the addressee of the question is uncertain about the answer. This is illustrated in the school test situation in (7b), where the teacher can be safely assumed to know the answer to his question.

(7) a. BOTH ADDRESSEE (B) AND SPEAKER (A) UNCERTAIN:

A to B: Ist dies wohl der richtige Weg?

$$
\text { Is this the right way }
$$

$\approx$ 'Would /could this be the right way?'

b. ONLY ADDRESSEE UNCERTAIN:

Teacher to student: Was ist wohl die Hauptstadt von Tansania? what is the capital of $T$.

$\approx$ 'What would be the capital of Tansania?'

In contrast, wohl is infelicitous in an interrogative clause whenever the addressee can be assumed to know the answer for sure. Typical contexts for this are so-called 'expert contexts', where the addressee is taken to be an 
expert concerning the question under discussion. A typical example is the airline context from Gunlogson 2001 in (8).

(8) A to an airline official: \#Geht der Flug wohl um 17.10 Uhr?

$$
\text { leaves the flight at } 5.10 \mathrm{pm}
$$

Interestingly, the epistemic reference points in (6) to (8) are identical to those of sentences not containing wohl. Doherty (1985:19) observes that the epistemic reference point of declaratives is the speaker, whereas the epistemic reference point of interrogatives is undetermined as long as it is not the speaker alone. If so, wohl simply inherits its epistemic reference point from the sentence type. In order to capture this dependency, one can assume that wohl stands in a tight structural relation to wherever the sentence type is structurally encoded. Following Rizzi (1997), we might say that a candidate for the structural encoding of sentence types is the force projection in the left periphery (see section 5).

\section{Wohl Does Not Form Part of the Proposition}

This section shows that the meaning of wohl does not contribute to the proposition expressed by an utterance, where proposition is to be understood as the truth-conditional, descriptive aspect of the meaning of the utterance. In this, wohl differs from (epistemic) modal auxiliary verbs and modal adverbials such as wahrscheinlich 'probably' and vermutlich 'presumably'. There are two kinds of evidence that wohl does not form part of the proposition.

\subsection{Intervention Effects with wohl}

First, the presence of wohl leads to intervention effects with variable binding. The data in (9) show that wohl cannot intervene between a bound variable and its binder. ${ }^{1}$ In (9a), wohl intervenes between a universal quantifier over events and the event variable of the embedded clause. In (9b), wohl intervenes

\footnotetext{
${ }^{1}$ An apparent exception to this generalisation is the grammaticality of wohl in restrictive relative clauses. Sentence (i) is grammatical even though wohl appears to intervene between the raised relative pronoun and its bound trace.

(i) Die Frau schätzte die Punktzahl, die $e_{1}$ sie wohl $\mathrm{t}_{1}$ erreichen würde. the woman guessed the score which she get would 'The woman guessed at the score that she would presumably get.'
}

Section 6 presents an argument to the effect that the relative LF positions of wohl, the relative pronoun and its trace in (i) are such that wohl does not intervene between the latter two. 
between the universal quantifier in the matrix clause and the bound subject pronoun in the embedded clause. ${ }^{2}$

a. *Wann immer $\mathrm{x}_{\mathrm{x}}$ ichwohl $\mathrm{e}_{\mathrm{x}}$ in Rom war, ging ich ins Kino. whenever I inR. was went I to-the movies INTENDED: 'Whenever I was presumably in Rome, I went to the movies.'

b. ${ }^{*} J e d e r_{\mathrm{x}}$ Postler wurde entlassen, weil $\quad e r_{\mathrm{x}}$ wohl in derDKP war. each postman was fired because he intheDKPwas INTENDED: 'Each postman was fired since he was presumably in the DKP.'

The relevant structural configurations are schematised in (10):

(10) a. whenever $r_{x}\left[\ldots\right.$ wohl $\left.\ldots e_{x}\right]\left[\ldots e_{x} \ldots\right]$

b. $\operatorname{each}_{\mathrm{x}} \ldots[\ldots \mathrm{x} \ldots$ wohl $]$

Notice that the ungrammaticality of $(9 \mathrm{a}, \mathrm{b})$ has nothing to do with wohl occurring in an embedded clause (see also Asbach-Schnitker 1977). This is shown by the grammaticality of (11), which is structurally similar to (9b) but involves no binding,

(11) Jeder Postler wurde entlassen,weil die Post wohl privatisiert wird. eachpostman was fired sincethepost privatised is 'Each postman was fired because the post will presumably be privatised.'

Similar intervention effects are observed with the discourse particle $j a$ by Kratzer (1999). Compare (12) with (9a) above.

(12) a. *Wann immer ich $j a$ in Romwar, ging ich ins Kino. whenever $I$ in $R$. was went $I$ to-the movies

b. whenever $\mathrm{x}\left[\ldots \mathrm{ja} \ldots \mathrm{e}_{\mathrm{x}}\right]\left[\ldots \mathrm{e}_{\mathrm{x}} \ldots\right]$

Kratzer's explanation for the ungrammaticality of (12) is as follows: the discourse particle $j a$ expresses an epistemic attitude of the speaker, namely that the proposition $\mathrm{p}$ expressed by an utterance $j a \mathrm{p}$ holds and that the facts described by p should - for all the speaker knows - be known to the hearer. Kratzer further assumes that epistemic attitudes in general cannot operate on open propositions, i.e. propositions containing unbound variables as in (12). This is because speakers can only entertain epistemic attitudes towards propositions that are fully specified as to when, where, and with whom. For this reason, the representation in (12b), in which $j a$ combines with an open

\footnotetext{
${ }^{2}$ Sentence (9b) is grammatical on another reading on which wohl takes scope over the entire causal connection of matrix clause and causal clause, meaning something like 'The speaker assumes that the reason for each employee's being fired is his or her membership in the German Communist Party.
} 
proposition containing the variable $e_{x}$, cannot be interpreted, resulting in ungrammaticality.

The fact that wohl shows the same intervention effects with binding as $j a$ suggests that wohl cannot operate on open propositions with unbound variables either. The ban on combining wohl with open propositions receives a straightforward explanation if wohl expresses an epistemic attitude, such as ASSUME (see section 5), which can operate only on fully specified, i.e. closed propositions. If so, wohl selects for propositions instead of forming part of them.

\subsection{Wohl Scopes over Question Formation}

The semantic behaviour of wohl in interrogative clauses, such as yes/no questions, supports the conclusion reached in the previous section. This section shows that wohl obligatorily scopes over (proto-)question formation, which in turn takes as its input the proposition expressed by the question. It follows that - at least at the level of semantic representation - wohl must be located in a position higher than the level of propositions.

With the noteworthy exception of Asbach-Schnitker (1977), most existing accounts of the discourse particle wohl have focused on declarative clauses. Doherty (1985: 80) even denies the possibility of wohl in yes/no questions altogether, contrary to fact (see e.g. (5b) above). The focus on wohl in declaratives is unfortunate because declaratives are inconclusive regarding the semantic location of wohl. This is because the result of applying wohl to a proposition can in principle be expressed as another proposition. Consider, for instance, the propositional paraphrase of (13).

(13) Peter ist wohl zuhause.

Peter is at.home

'The speaker assumes that Peter is at home.'

Things are different in questions, however. Semantically, questions can be modelled as sets of alternative propositions that are built on the basis of the proposition expressed by the question (Hamblin 1973; von Stechow 1991). For instance, the meaning of the yes/no question in (14a) can be represented as in (14b) (after proto-question formation; see Karttunen 1977) and (14c) (after addition of the illocutionary question operator '?')

(14) a. Does it rain?

b. $\Rightarrow$ it rains, it does not rain $\}$

c. $\Rightarrow$ ? it rains, it does not rain

$\approx$ 'Tell me which of the alternatives is correct: It rains or it doesn't.' 
The input for the formation of the proto-question in (14b) is the propositional content of the question in (14a): namely, the proposition it rains.

The semantics of yes/no questions allow for the following prediction concerning the semantic interpretation of wohl:

(15) If wohl made up part of the propositional meaning of an utterance, a proposition containing wohl should behave just like other propositions under question formation.

In particular, the semantic contribution of wohl should be part of the input for proto-question formation. This prediction is not borne out, as shown by the following argument. If the prediction in (15) were correct, we would expect (16a) to have the semantic representation in (16b). In particular, we would expect the semantic contribution of wohl, i.e. the epistemic attitude ASSUME, to take scope under question formation, and hence under negation (the relevant elements are indicated in bold face).

(16) a. Ist Hein wohl aufSee?

Is Hein at sea

b. ? $\{$ assume(addressee,Hein at sea), $\neg$ assume(addressee,Hein at sea) $\}$ $\approx^{6}$ Tell me which is correct:

You assume that $\mathrm{H}$. is at sea,or you don't assume that $\mathrm{H}$. is at sea'

As the paraphrase shows, (16b) represents a question about the epistemic state of the addressee, rather than about Hein's whereabouts. It simply questions the addressee's assumptions concerning Hein's being at sea. Therefore, (17) (or rather its German equivalent) should be a felicitous answer to (16a), contrary to fact.

\section{(17) No, I don't assume that Hein is at sea (\# as an answer to (16a))}

The answer in (17) is compatible with the addressee having no assumptions whatsoever about Hein's whereabouts, but this is not what somebody who asks (16a) is interested in.

Rather, he or she is interested in the whereabouts of Hein, at the same time allowing for a certain degree of uncertainty on the part of the addressee. This is captured by the semantic representation in (18), with wohl scoping over question formation and negation.

(18) ? ASSUME $\{$ Hein is at sea, $\neg$ Hein is at sea\}

$\approx$ 'Tell me your assumption concerning Hein's being at sea or his not being at sea.'

The representation in (18) correctly predicts that the following are felicitous answers to (16a) (see Asbach-Schnitker 1977: 50): 
(19) vermutlich (ja/nein) 'presumably yes/no', wahrscheinlich (ja/nein) 'probably yes/no', Ich denke (ja/nein) 'I think/guess so/not' ...

Summing up, it was shown that structures such as (16b) with wohl scoping under question formation cannot be the correct semantic representation of yes/no questions containing wohl. The correct representation is given in (18), with wohl scoping over question formation. Now, if question formation takes scope over propositions (mapping them onto sets of propositions), and if wohl takes scope over question formation, it follows that wohl cannot form part of the proposition, but must be located in a higher position semantically.

Notice finally that the semantic behaviour of wohl in questions differs from that of (epistemic) modal auxiliaries and modal adverbials. Unlike wohl, the latter take scope under negation, and hence under question formation in interrogatives. This is illustrated for the epistemic modal auxiliary müssen 'must' in (20a), which is paraphrased as (20b). ${ }^{3}$

\section{a. Muss Hein in das Unwetter geraten? must Hein in the thunderstorm get 'Must Hein get into the thunderstorm?'}

b. Is it necessarily so that Hein gets into the thunderstorm, or is it not necessarily so that Hein gets into the thunderstorm? NEG $>>$ MUST

The data in (20a, b) show that modal expressions do form part of the proposition, clearly setting these apart from the discourse particle wohl. Only wohl (and possibly other discourse particles) does not form part of the proposition, something that any analysis of such expressions must account for.

\section{Wohl Triggers No Conventional Implicatures}

In the preceding section, it was shown that the semantic scope of wohl is very high, with wohl outscoping even question formation. This makes it, at first

\footnotetext{
${ }^{3}$ Unfortunately, Y/N-questions with modal adverbials such as vermutlich 'presumably', which at first sight is rather close in meaning to wohl, are only marginally acceptable. To the degree that they are acceptable, they behave like yes/no questions with epistemic modal auxiliaries. This is shown by (i), in which the modal adverbial takes scope under negation.

(i) ??Wird Hein vermutlich in ein Unwetter geraten? will Hein presumably in a thunderstorm get

'Tell me what is correct: It is presumably so that Hein will get into a thunderstorm, or it is not presumably so that Hein will get into a thunderstorm.'

Without getting into the reasons for why (i) is only marginally acceptable (see Doherty 1985 : 41 for a possible explanation), it is important to point out that substitution of wohl for vermutlich in (i) results in wellformedness. This goes to show that the two expressions differ despite initial appearances to the contrary.
} 
sight, look similar to another class of expressions that also outscope question formation. The class in question is the class of expressions that trigger conventional implicatures, e.g. expressives such as verdammte 'damned', parentheticals such as wie $d u$ behauptest 'as you claim', and particles triggering implicatures such as auch 'also'. Following Karttunen \& Peters (1979), these elements can be analysed as contributing to an independent semantic level of implicature that stands next to the level of asserted meaning: $<$ ASS, IMPL $>$.

Looking at how expressions that trigger implicatures behave in interrogatives, (21a) shows that the expressive verdammte scopes over question formation. This is expected if the meaning of verdammte is processed at a semantic level different from that of question formation, as sketched in (21b).

(21) a. Hast du den verdammten Hund gesehen?

Have you the damned dog seen

'Have you seen that damned dog?'

b. $<[[$ Have you seen that $\operatorname{dog} \mathrm{z}$ ?]], speaker does not like $\mathrm{z}>$ questioned implicated meaning

Given the similar behaviour of wohl and implicature-triggering expressions in questions, one could falsely assume that wohl, too, contributes its meaning to an independent semantic level. On this line of reasoning, it would do so by triggering a conventional implicature to the effect that the addressee of the question is not absolutely sure about his or her answer. This is illustrated in (22).

(22) Potential semantic analysis of questions with wohl (to be rejected!)

$[[$ wohl $\mathrm{p} ?]]=<? \mathrm{p}, \quad$ addressee is not sure concerning $\mathrm{p}>$

$$
\text { questioned implicated meaning }
$$

This section argues that, despite first appearances, the discourse particle wohl should not be treated on a par with expressions that trigger implicatures. Consequently, it should not be taken to contribute to an independent semantic level of implicature. The argument proceeds by showing that wohl differs from elements triggering implicatures in two important respects.

\subsection{Scopal Behaviour}

The first difference concerns the scopal behaviour in embedded contexts. As the following examples show, expressives (e.g. (23)), parentheticals (e.g. (24)), and particles that trigger implicatures (e.g. (25)) can or must scope out of embedded clauses (see, e.g., Karttunen \& Peters 1979; Potts 2002a, b). 
(23) a. Bushsagt, dass die verdammten Republikaner Hilfe verdienen. Bush says that the damned Republicans support deserve

b. $<$ B. says that the _ Rep.s deserve support; Speaker dislikes the Rep.s $>$

(24) a. Wenn der Smutje, wie ichmeine, betrunken ist, gibt es keinEssen. if thecook as I think drunk is there is no food

b. <If the cook__ is drunk, there will be no food; I think the cook is drunk>

(25) a. Der Kapitän weiß, dass der Smutje auch betrunken war. the captain knows that the smutje also drunk was

b. <The capt. knows that the cook__was drunk; somebody else was drunk>

Since the semantic contribution of all these expressions is processed at an independent semantic level of implicature, such insensitivity towards embedding does not come as a surprise.

Unlike the above expressions, though, wohl never scopes out of embedding contexts. This is shown in examples (26)-(28). (26a) does not say that the speaker is uncertain as to whether the SPD deserves support. Likewise, (27a) does not say that the speaker has any assumptions about the cook's being or not being drunk. And in (28a), wohl has to be interpreted with respect to the epistemic state of the matrix subject, leading to incompatibility with the matrix verb wissen 'to know'.

(26) a. Schröder sagt, dass die SPD wohl Hilfe verdient. Schröder says that theSPD support deserves

b. $\neq<\mathrm{S}$. says that the SPD_deserves support; speaker unsure if the SPD deserves support $>$

(27) a.*?Wennder Smutje wohl betrunken ist, gibt es kein Essen. if thecook drunk is there is no food

b. $\neq<<$ If the cook_ is drunk, there will be no food; speaker unsure if the cook is drunk>

(28) a. *Die Deern weiß, dass Hein wohl auf See ist. the girl knows that Hein at sea is

b. $\neq<$ The girl knows that Hein__is at sea; speaker unsure if Hein is at sea $>$

The different scope taking behaviour of wohl therefore suggests that it does not trigger a conventional implicature. 


\subsection{Wohl Does Not Introduce a Surplus Meaning}

The second difference concerns the fact that all expressions that trigger conventional implicatures add a second level of meaning to the descriptive content asserted by a sentence. This was already illustrated in (23)-(25). One could say that these expressions contribute a surplus value to the mere propositional content of a clause. This state of affairs is schematised in (29), where $\alpha$ stands for some implicature-triggering expression.

$$
\begin{aligned}
& {[[[p \ldots \alpha \ldots]]]=<[[p-\alpha]], \quad[[\alpha]]>} \\
& \text { asserted implicated meaning }
\end{aligned}
$$

According to (29), the meaning of a sentence containing an implicaturetriggering expression $\alpha$ equals the meaning of the sentence without $\alpha$ plus the meaning of $\alpha$.

The same does not hold for wohl. Crucially, a sentence containing wohl does not say that the state of affairs described by the sentence without wohl holds. Rather, the presence of wohl has the effect that the state of affairs described by the sentence is still unresolved. To give an example, a felicitous use of (1b), repeated as (30a), does not allow for the conclusion that Hein is indeed at sea, whatever the precise meaning of wohl:

(30) a. Hein ist wohl auf See.

Hein is at sea

b. $*<$ Hein is _ at sea, [[wohl]]>

Summing up this section, it was shown that there are good reasons not to treat wohl as an expression that triggers conventional implicatures. First, the scopal behaviour of wohl is not as free as that of typical implicature-triggering expressions. This argues against processing the meaning of wohl at an independent semantic level of implicatures. Second, unlike implicaturetriggering expressions, wohl does not add meaning to the descriptive content of an utterance. Rather, the presence of wohl seems to change the kind of propositional commitment towards this descriptive content (Green 2000). It is this latter intuition that underlies the semantic analysis to be put forward in the following section.

\section{Wohl as a Modifier on Sentence Type Operators}

This section presents the syntactic and semantic analysis of wohl. It is argued that wohl semantically modifies sentence types, or rather those elements that encode the sentence type structurally. As indicated at the end of the previous section, its semantic contribution consists in expressing a particular kind of propositional commitment. I further assume for declarative and interrogative 
clauses that their sentence type is encoded in the form of the privative features decl(arative) and int(errogative). Since these features are located in the head of a functional projection in the left periphery of the clause, wohl has to move there covertly if it is to modify them. Somewhat anticipating the discussion to follow, the two main ideas behind the analysis are given in (31):

(31) a. Semantically, wohl indicates a particular kind of propositional commitment.

(Green 2000)

b. Syntactically, wohl moves to the specifier of the functional projection ForceP at LF.

(Rizzi 1997)

The assumption that wohl is interpreted in a high peripheral position explains its - at first sight contradictory - scopal behaviour. On one hand, we have seen that wohl does not form part of the proposition and must be interpreted above proto-question formation (see section 3). This observation is accounted for if wohl is interpreted in a high functional projection above the sentence type feature. On the other hand, we have seen that its scopal behaviour is not as free as that of expressions that trigger conventional implicatures. Again, this observation is accounted for if wohl is interpreted in a high functional projection but still inside the clause. This state of affairs is summarised in (32):

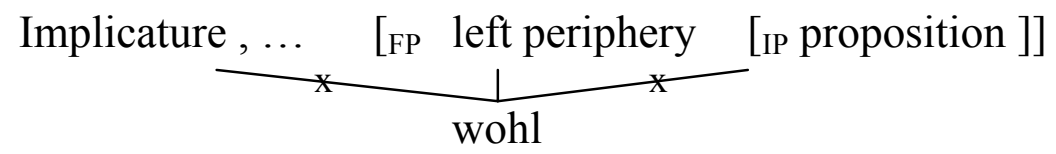

\subsection{Semantic Assumptions}

In section 4.2, it was already mentioned that sentences containing wohl are weaker in their assertive force than sentences not containing wohl. From wohl $p$ it does not follow that $p$, but only that $p$ is not implausible. In other words, the presence of wohl in an utterance $U$ prevents a 'strong commitment' to the proposition $p$ expressed by $U$, where 'strong commitment' here roughly corresponds to Stalnaker's (1978) notion of 'assertion'.

Following Stalnaker, an assertion normally introduces a proposition $p$ into the Common Ground (CG), where $\mathrm{CG}$ is the set of assumptions mutually accepted by the discourse participants. By way of example, an utterance of (33a) adds the proposition $p$ in (33b) to the $\mathrm{CG}_{\mathrm{i}}$ in (33c), yielding the new or updated $\mathrm{CG}_{\mathrm{j}}$ in $(33 \mathrm{~d})$.

(33) a. Hein ist auf See.

Hein is at sea

b. $\mathrm{p}=[[$ Hein is at sea $]]$

c. $\mathrm{CG}_{\mathrm{i}}=\left\{\ldots, \mathrm{p}_{\mathrm{x}}, \mathrm{p}_{\mathrm{y}}, \mathrm{p}_{\mathrm{z}}, \ldots\right\}$

(CG before utterance of (33a)) 
d. $\mathrm{CG}_{\mathrm{j}}=\left\{\ldots, \mathrm{p}_{\mathrm{x}}, \mathrm{p}_{\mathrm{y}}, \mathbf{p}, \mathrm{p}_{\mathrm{z}}, \ldots\right\}$

(CG after utterance of (33b))

The introduction of $p$ into the $\mathrm{CG}$ is informative because it reduces the number of possible worlds that are compatible with the CG. Before an utterance of (33a), the CG is compatible with worlds in which Hein is at sea as well as with worlds in which he is not. After the utterance of (33a), the CG is only compatible with the former.

An utterance of wohl p, on the other hand, is not informative in the same sense. Unlike in the case of normal assertion (or: strong commitment), it does not lead to an introduction of $p$ into the CG. Rather it leads to the introduction of a different object, namely a speaker's $x$ hypothetical commitment to $p$, here abbreviated as ASSUME(x,p).

(34) a. Hein ist wohl auf See.

$$
\text { Hein is at sea }
$$

b. $\mathrm{p}=[[$ Hein is at sea $]]$

c. $\mathrm{CG}_{\mathrm{i}}=\left\{\ldots, \mathrm{p}_{\mathrm{x}}, \mathrm{p}_{\mathrm{y}}, \mathrm{p}_{\mathrm{z}}, \ldots\right\} \quad$ (CG before utterance of (34a))

d. $\mathrm{CG}_{\mathrm{j}}=\left\{\ldots, \mathrm{p}_{\mathrm{x}}, \mathrm{p}_{\mathrm{y}}, \operatorname{ASSUME}(\mathbf{x}, \mathbf{p}), \mathrm{p}_{\mathrm{z}}, \ldots\right\}(\mathrm{CG}$ after utterance of $(34 \mathrm{~b}))$

As in (33), the CG before an utterance of (34a) is compatible with worlds in which Hein is at sea and with worlds in which he is not. Unlike in (33), however, the CG after the utterance of (34a) is still compatible with both types of worlds. The utterance of (34a) is informative only in so far as the CG is incompatible with worlds in which the speaker $x$ does not profess a hypothetical commitment to $\mathrm{p}$.

In brief, an utterance of wohl $p$ differs from ordinary assertion in that it does not express a strict commitment towards $p$. It only expresses a weaker commitment towards $\mathrm{p}$, namely an idiosyncratic commitment on the side of the speaker that $p$ is likely to be the case. This result ties in with Doherty's (1979) analysis of wohl as a 'hypothesis functor'. (35) is a first approximation of the meaning of wohl:

(35) $[[$ wohl p ] $]=\operatorname{ASSUME}(x, p)$

(with $\mathrm{x}=$ speaker, hearer, or both)

More generally, the present analysis implies that there are different kinds of declarative sentences. Adopting an idea from Green 2000, we can say that declaratives can be used to make assertions with different strength regarding their degree of commitment towards the proposition expressed: 
[...] it is insufficient merely to describe speakers as committed to propositions and other semantic contents [e.g. sets of propositions, MZ]; accuracy requires also tracking the mode of that commitment by adverting to the force of the speech acts that engendered it. (Green 2000: 444)

Here, I assume that a commitment is strict in the default case (corresponding to Stalnaker's (1978) assertion), but it can also come in the weaker forms of assumption (e.g. with wohl), mere speculation, conjecture, etc.

Turning to interrogatives, these too come in different kinds. On their basic use, they make a request for an assertion by the hearer, but the requested assertion can have different degrees of propositional commitment. It can be strict, or it can be an assumption, a speculation etc.

Let us finally come back to the question of what the communicative gain is of using an utterance wohl $p$ if it does not lead to the inclusion of $p$ in the CG, but only to the inclusion of an idiosyncratic commitment to $p$ on the side of the speaker. Again, the answer is found in Green 2000: 467.

Manifesting one's idiosyncratic commitments will facilitate communication in part by making clear an interlocutor's dialectical status, that is, it will help make clear to other interlocutors what sorts of utterance an interlocutor is likely to accept or, on the other hand, to challenge. Similarly, it will make clear what sorts of questions an interlocutor is apt to reject or, alternatively, to endorse and attempt to answer.

\subsection{Syntactic Assumptions}

The syntactic part of the analysis rests on two assumptions. Following Rizzi (1997), I assume that the specification of a sentence type, e.g. as declarative or interrogative, takes place in the highest position in the expanded left periphery, namely in ForceP:

$$
\begin{gathered}
{\left[\text { ForceP Force }^{0} \ldots[\text { TopP }[\text { FocP }[\text { FinP }[\ldots\right.} \\
\text { decl / int }
\end{gathered}
$$

The head of ForceP can host the features decl and int, respectively. Apart from determining the sentence type and therefore the semantic type of its denotation (decl: proposition; int: set of propositions), these features also determine the epistemic reference point against which the utterance is evaluated (see section 2). With decl, the epistemic reference point is the speaker. With int, the epistemic reference point is the addressee or addressee and speaker together (see Doherty 1985).

Extending Rizzi's analysis, I would like to argue that the functional projection ForceP is not only the locus of sentence type determination. In addition, it can be assumed to encode the strength of the propositional commitment, as outlined in the preceding paragraph. This modification in the 
strength of commitment can be brought about by a modifying expression that is located in the specifier of ForceP.

\subsection{A Compositional Analysis of wohl}

I would like to argue that the discourse particle wohl is just such a modifier on sentence types. Since it has not yet lost its categorical status as an adverb (see section 1.1), it is base-generated at the edge of VP (see Fukui 1986), where it also occurs in the overt syntax, as shown in (37a). At LF, wohl moves covertly to the specifier of ForceP. This LF-movement to SpecForceP has the effect of (i) modifying the strength of commitment, and (ii) determining the epistemic reference point under Spec-Head-agreement with Force ${ }^{0}$, as shown in (37c). The result can then combine with the illocutionary operator ASSERT (37d) (see also Doherty 1985; Abraham 1991).

(37) a. [Forcep decl $_{\text {speaker }}[$ TopP Hein [FinP ist [vP wohl [vp auf See ]]]]].

$$
\text { Hein is at sea }
$$

b. [ForceP wohl $_{\mathrm{i}}$ decl $_{\text {speaker }}\left[\mathrm{TopP}\right.$ Hein [FinP ist [vp $\mathrm{t}_{\mathrm{i}}[\mathrm{vP}$ auf See]]]]]

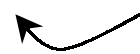

c. $\varnothing(\mathrm{x}, \mathrm{p}) \rightarrow \operatorname{ASSUME}($ speaker, $\mathrm{p})$

(with ' $\varnothing$ ' = default strict commitment)

d. ASSERT (ASSUME (speaker, p))

The syntactic derivation for interrogative yes/no questions, such as (38a), proceeds in essentially parallel fashion, neglecting a possible difference in the positioning of the finite verb.

(38) a. Hat Hania wohl auch ihren Chef eingeladen? has Hania also her boss invited

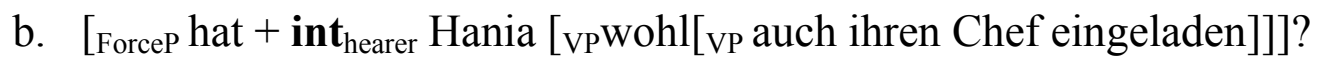

c. [ForceP wohl $_{\mathrm{i}}$ int $_{\text {hearer }}$ Hania [vp $\mathrm{t}_{\mathrm{i}}$ [vp auch ihren Chef eingeladen]]]?

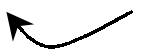

d. $\varnothing(\mathrm{x},\{\mathrm{p}, \neg \mathrm{p}\}) \rightarrow \operatorname{ASSUME}($ hearer, $\{\mathrm{p}, \neg \mathrm{p}\})$

e. ?(ASSUME (hearer, $\{p, \neg p\})$ ) ('?'=illocutionary question operator)

The meaning of (38a) in (38e) is compositionally derivable in three steps. It involves (i) proto-question formation triggered by the feature int in Force ${ }^{0}$; (ii) functional application of the meaning of wohl in SpecForceP; and (iii) the addition of the illocutionary question operator?. The semantic values for int and wohl are given in (39ab).

a. $[[$ int $]]=\lambda p .\{p, \neg p\}$ 
b. $[[$ wohl $]]=\lambda P . \operatorname{ASSUME}($ hearer, $\{\mathrm{q} \mid \mathrm{q} \in \mathrm{P}\})$

Int takes a proposition as its argument and maps it onto a set of alternative propositions. Wohl takes a set $\mathrm{P}$ of propositions as argument and maps it onto a hypothetical commitment of the hearer towards the elements of $\mathrm{P}$. The entire semantic derivation proceeds in parallel with the structural build-up and is sketched in (40). The semantic values of all nodes and terminal elements are given in bold face.

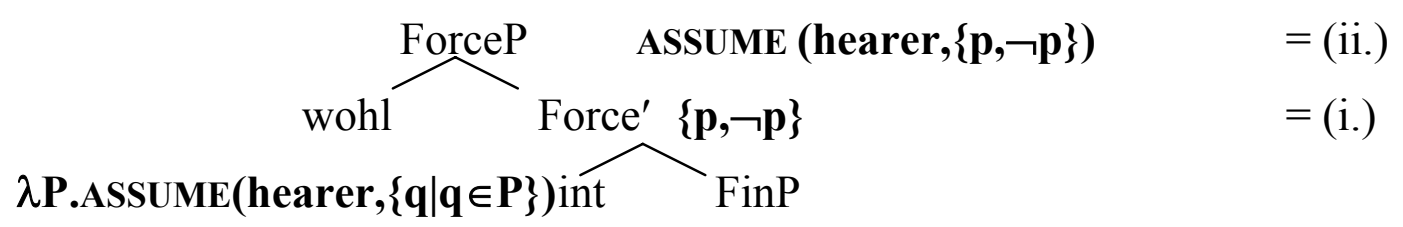$$
\lambda \mathbf{p} .\{\mathbf{p}, \neg \mathbf{p}\} \quad \mathbf{p}
$$

The meaning of declarative clauses containing wohl, such as in (37), can be derived in analogous fashion. The only difference stems from the fact that in declaratives wohl takes a proposition as complement, not a set of propositions. One therefore has to assume a certain flexibility in the selectional requirements of wohl. ${ }^{4}$

Summing up, the semantic derivation in (40), based on the syntactic derivation in (38), accounts for the scopal behaviour of wohl observed in section 3. In particular, the high structural position of wohl in Spec,ForceP explains why it scopes over question formation, which takes place in Force ${ }^{0}$. At the same time, the meaning of wohl is processed at the same semantic level as the rest of the clause. This explains the scopal differences between wohl and the expressions that trigger conventional implicatures that were pointed out in section $4 .^{5}$

\footnotetext{
${ }^{4}$ Alternatively, one could treat a proposition as equivalent to the set containing just this proposition as its only member, and shift its type accordingly. This way, wohl would always select for sets of propositions.

${ }^{5}$ Potts (2002b) shows a way to integrate the denotation of implicature-triggering expressions into a one-dimensional semantic representation. He does so by treating implicaturetriggering expressions as partially defined identity functions that only give a value when their implicature is met, and no semantic value otherwise. If correct, the difference between wohl and implicature-triggering expressions is not so much a difference of the level of semantic representation, but rather a difference in denotation. Unlike expressions triggering conventioanl implicatures, wohl does not denote partially defined identity functions, giving rise to the observable scope restrictions.
} 


\subsection{Cross-Linguistic Evidence}

The analysis of the discourse particle wohl as occupying a position in the left periphery at LF is largely motivated by semantic (scope) considerations. However, there is some cross-linguistic evidence to support it. In some languages, the counterpart of wohl occurs in the periphery of the clause in overt syntax, either in the highest functional projection or adjoined to the entire clause.

The Finnish counterpart to wohl in yes/no questions is realised as a suffix in the highest functional head.

(41) a. On-ko-han Pentti kotona? is- Q-wohl Pentti at home

'Would Pennti be at home?'

b. Sa- isin- ko-han laskun? , got- subj1sG- $Q$-wohl billACC

'Could I get the bill?'

English declaratives make use of sentence-final tags (possibly adjoined to ForceP) in order to express the weaker propositional commitment of assumption that is associated with wohl.

(42) A: Where is Peter?

$\mathrm{B}$ : [He is at home], isn't he?

Similar peripheral tags are employed in the German dialects as an alternative to wohl:

(43) oder? 'or', wa? 'what' (Berlin), ne? 'not' (Rhineland), gell/gelt? 'valid' (Upper German), ge? (Palatine), ...

Looking beyond wohl, other expressions that contribute to the expressive rather than to the descriptive content of a clause are expected to occur in a peripheral position as well. Confirming this expectation, Munaro \& Poletto (2004) show that various Northern Italian dialects exhibit a number of particles with expressive content that indeed occupy a peripheral position in overt syntax. ${ }^{6}$

\footnotetext{
${ }^{6}$ This last observation has to be treated with care, though. It may well turn out that the syntactic and the semantic properties of what at first sight look like similar particles differ even though all of them occur in the left periphery. See the brief discussion of the differences between the German discourse particles $j a$ and wohl at the end of section 6, and Zimmermann 2004 for further discussion.
} 


\subsection{Accounting for the Properties of wohl}

Apart form explaining the scopal properties of wohl, the analysis also accounts for the remaining properties of wohl that were observed in sections 1-4. First, the impossibility of embedding wohl under the verb wissen 'to know' (see (4b) in section 1.2) follows from selectional restrictions between the matrix verb wissen and the ForceP that it selects for. Wissen can as little select for a ForceP that is modified by wohl, as in (44a), as the verb sich fragen can select for a ForceP containing the feature declarative, as shown in (44b).

(44) a. *ich weiß, wohl-decl

I know

b. *ich frage mich, decl

I wonder

Second, the restriction to declarative and interrogative clauses (see section 1.3) follows from the fact that a weak propositional commitment such as ASSUME can only be evaluated with respect to what can be known, i.e. at epistemically accessible indices (encoded by and only by the features $d e c l$ and int).

Third, the fact that the epistemic reference point of wohl depends directly on that of the sentence type (see section 2) is accounted for, since wohl can inherit it from the sentence type feature in Force ${ }^{0}$ under Spec-head-agreement.

Fourth, the intervening effects of wohl with variable binding (see section 3.1) follow from the fact that wohl must take closed propositions as arguments. From its high structural position in SpecForceP, it is able to do so.

Finally, the analysis can account for certain illocutionary effects showing up with wohl in declarative and interrogative clauses. In certain contexts, declaratives with wohl can be used as questions, as in (45a). Interrogatives with wohl can sometimes be used as directives, as in (45b).
a. Das ist wohl dein Freund?
that is
your boyfriend
$\rightarrow \quad$ Question
'That is your boyfriend, isn't it?'
b. Bist du wohl still?
$\rightarrow \quad$ Directive
are you quiet
'Will you be quiet!'

Since the illocutionary effects in (45) are restricted to particular contexts, they cannot be directly attributed to the meaning of wohl. Below, it is shown that the illocutionary effects in (45ab) are conversational implicatures that arise whenever the literal meaning of a clause containing wohl is infelicitous in the context of the utterance. Instead of assuming that the speaker has made an infelicitous or irrelevant utterance, the hearer will apply some reasoning in order to save the utterance, in line with Grice's (1975) 'Principle of 
Cooperativity'. The following is a brief sketch of how such a line of reasoning could look for the examples in $(45 \mathrm{a}, \mathrm{b})$.

A possible context that would give rise for a question use of (44a) is a situation in which speaker A encounters an old friend B coming down the street and holding hands with a man. On meeting, A utters (45a), thus triggering the following line of thought on hearer B's side (with $p=$ the proposition 'this is the hearer's boyfriend'):

(46) a. A has chosen ASSERT (ASSUME (speaker, p)) instead of the stronger (since more informative) ASSERT ( $\varnothing$ (speaker, $p)$ ).

b. If A knew that $\mathrm{p}$, she would have chosen $\operatorname{ASSERT~} \varnothing($ speaker, $p))$. (maxim of quantity).

c. A is not sure whether or not $\mathrm{p}$.

d. A can safely assume that I know whether or not $\mathrm{p}$.

e. Therefore, A's utterance is uninformative, hence irrelevant.

f. A did not intend to make an irrelevant utterance. (principle of cooperativity)

$\Rightarrow$ A would like me to tell her whether or not $\mathrm{p}$.

A similar line of reasoning on the hearer B's side, given in (47), accounts for the directive use of the interrogative clause in (45b).

(47) a. Speaker A literally asks me to answer his question whether or not I am quiet and indicates that I am uncertain about my currently being quiet.

b. It is impossible that I am not certain about a property that I myself can control, and A also knows this.

c. Besides, A has available to him all the necessary information to answer his question.

d. A's utterance is inappropriate and irrelevant.

e. A did not intend to make an irrelevant utterance. (principle of cooperativity)

$\Rightarrow$ A tells me to be quiet.

(directive)

As pointed out by Asbach-Schnitker (1977), interrogative directives such as (45b) have to meet two conditions. First, the question must make direct reference to a property of the hearer, i.e. they must contain a verb in $2^{\text {nd }}$ person. Second, the property of the hearer must be under the control of the hearer. Only the satisfaction of both conditions makes such sentences infelicitous or inappropriate on their literal reading, thus triggering a 
pragmatic reinterpretation by way of conversational implicature. Finally, it should be noted that this kind of explanation directly carries over to other pragmatic effects that are observable with wohl, e.g. certain effects of politeness and irony (see Zimmermann 2004).

I conclude that the analysis of wohl as a sentence-type modifier in Spec,ForceP accounts not only for its scopal properties, but also for its other characteristic properties, including certain illocutionary effects.

\section{Open Issues}

This section briefly addresses a number of open issues. In the interest of space, I will restrict myself to merely pointing out the relevant problems and possible ways to approach them. For a more detailed discussion of these issues, the reader is referred to Zimmermann 2004.

The first open issue concerns DP-internal occurrences of wohl. As shown in section 1.1 and illustrated again in (48), wohl can occur DP-internally.

(48) Peter ist in [DP das wohl beste [NP Restaurant von Berlin]] gegangen. Peter is in the best restaurant of Berlin gone 'Peter went to a restaurant that is arguably the best in Berlin.'

The paraphrase makes clear that wohl here does not take scope over the entire proposition, but only over the DP. The fact that Peter went to some restaurant is not in doubt in (48). This shows that wohl is not interpreted in Spec,ForceP of the matrix clause in (48), giving rise to the question in which position wohl is interpreted. A possible solution would be to assume that the functional architecture of at least some DPs contains a Force projection as well. This would be feasible if these DPs could be analysed as propositional expressions or phases (see Chomsky 2001), an assumption not altogether implausible given the often stressed structural parallels between CPs and DPs (see, e.g., Abney 1987). On this view, DP-internal wohl would be interpreted on the completion of the DP-phase (but see Matushansky 2003 for arguments against treatung DPs as phases). ${ }^{7}$

The second open issue concerns the co-occurrence of wohl and whexpressions. Since Spec,ForceP is reserved for sentence-type modifiers such as wohl, the wh-expression in (49) must be located in another, lower position.

(49) Wen hat Peter wohl eingeladen? who has Peter invited

\footnotetext{
${ }^{7}$ Another alternative would be to allow for constituents of any syntactic and semantic type to be associated with an evaluation function. On this view, the restriction of wohl to VP and DP in the overt syntax would follow from its categorial status as adverb alone (see section 1.1).
} 
Given that $w h$-expressions are inevitably focused expressions, a natural landing site for the overtly moved wh-expression in (49) would be the specifier of Foc(us)P in Rizzi's (1997) expanded left periphery. Notice that, on such an analysis, the finite verb in questions cannot be assumed to be in Force ${ }^{0}$ like the interrogative complemetizer $o b$ 'if' in embedded questions. Rather, the finite verb in (49) must be in a lower position, e.g. in the head of FinP (see Grewendorf 2002: 241). A tentative LF-structure for (49) is given in (50). Notice that wohl does not intervene between the $w h$-expression and the trace bound by it in (50).

(50) [ForceP wohl $_{\mathrm{i}}$ int [FocP Wen ${ }_{\mathrm{j}}$ Foc [FinP hat Peter $t_{\mathrm{i}} \mathrm{t}_{\mathrm{j}}$ eingeladen]]]

The structure in (50) also paves the way to a solution for a related problem. In connection with the intervention effects of wohl with variable binding in section 3.1, it was mentioned that these intervention effects do not show up in restrictive relative clauses, which also involve variable binding. As a result, wohl (unlike the discourse particle $j a$ ) is licit in restrictive relative clauses, as shown in (51a). Assuming that the relative pronoun in (51a) moves to the same position as the $w h$-expression in (50), namely to SpecFocP, we get (51b) as the LF-structure of the relative clause.

(51) a. Die Frau wählte den Mann, der wohl am reichsten war. the woman chose the man who at-the richest was 'The woman chose that man that seemed to be the richest.'

b. [ForceP $\mathbf{w o h} \mathbf{l}_{\mathbf{i}} \operatorname{decl}\left[\right.$ FocP $\mathbf{d e r}_{\mathbf{j}}$ Foc [FinP $\mathbf{t}_{\mathbf{j}} \mathbf{t}_{\mathrm{i}}$ am reichsten war]]]

In (51b), wohl does not intervene between the raised relative pronoun and the trace bound by it. For semantic consequences of this line of reasoning see Zimmermann 2004.

A final point to be addressed concerns the question of whether the analysis proposed for wohl should be extended to other discourse particles such as $j a$. There is preliminary evidence that it should not. Unlike wohl, the particle $j a$ (discussed in Jacobs 1991, Kratzer 1999, and many others) does not modify the strength of the commitment to the proposition expressed. Rather, it adds a surplus meaning to the effect that the speaker indicates that he has good reason to believe that the hearer is aware of the state-of-affairs described by the proposition. In short, the particle $j a$ seems to behave more like elements that trigger conventional implicatures (see section 4). The different status of $j a$ is confirmed by the fact that $j a$ obligatorily takes syntactic and semantic scope over wohl when the two particles co-occur. 
(52) Heute ist ja wohl Müllers letzter Arbeitstag. today is Müller's last day.at.work $=$ Speaker assumes that today is Müller's last day at work and expresses his expectation that the hearer should entertain the same assumption on the base of evidence available to him.

At least from a semantic point of view, then, $j a$ should not be treated as a sentence-type modifier like wohl, but rather as an expression modifying the illocutionary operator ASSERT (see Jacobs 1991).

\section{Conclusion}

In this article, I have presented an analysis of the discourse particle wohl as a modifier of sentence-type operators. Since the information pertaining to the sentence type is encoded in a high functional projection in the left periphery of the clause, namely in ForceP, wohl must covertly move to SpecForceP. The semantic function of wohl is to indicate a weakened commitment to the proposition expressed by the clause.

The analysis presented captures the semantic contribution of wohl in declaratives and interrogatives. It accounts for the observable distributional restrictions on wohl and captures the peculiar scopal behaviour of wohl by means of a fully compositional procedure. Furthermore, it paves the way for a unified analysis of wohl and its counterparts in other languages where these occur in a peripheral position in overt syntax. Finally, the analysis spells out in more detail the semantic content of ForceP, a functional projection normally motivated on purely syntactic grounds.

\section{References}

Abney, Steven. 1987. The English Noun Phrase in its Sentential Aspect. Ph.D. diss., MIT, Cambridge, MA.

Abraham, Werner. 1991. Discourse Particles in German: How Does Their Illocutive Force Come About? In Werner Abraham, ed., Discourse Particles. Benjamins, Amsterdam/Philadelphia, pp. 203-252.

Asbach-Schnitker, Brigitte. 1977. Die Satzpartikel 'wohl'. In Harald Weydt, ed., Aspekte der Modalpartikeln. Narr, Tübingen, pp. 38- 62.

Chomsky, Noam. 2001. Derivation by Phase. In Michail Kenstowicz, ed., Ken Hale: A Life in Language. MIT Press, Cambridge, MA, pp. 1-52.

Doherty, Monika. 1979. Wohl. Linguistische Studien, Reihe A. Arbeitsbericht 60, pp. 101140.

Doherty, Monika. 1985. Epistemische Bedeutung. Akademie Verlag, Berlin.

Fintel, Kai von. 2002. Unembeddable Meanings. The Meanings of Epistemic Modality. Paper presented at Sinn und Bedeutung 7, Universität Konstanz, 5 October 2002. 
Fukui, N. 1986. A Theory of Category Projection and Its Application. PhD diss., MIT, Cambridge, MA.

Green, Mitchell S. 2000: Illocutionary Force and Semantic Content. Linguistics and Philosophy 23: 435-473.

Grewendorf, Günther. 2002. Minimalistische Syntax. Francke, Tübingen und Basel.

Grice, Paul. 1975. Logic and Conversation. In P. Cole \& L. Morgan, eds., Syntax and Semantics 3: Speech Acts. Academic Press, New York, 41-58.

Gunlogson, Christine. 2001. True to Form: Rising and Falling Declaratives as Questions in English. Ph.D. diss., UCSC, Santa Cruz.

Hamblin, Charles L. 1973. Questions in Montague English. Foundations of Language 10: 41-53.

Jacobs, Joachim 1991. On the Semantics of Modal Particles. In Werner Abraham, ed., Discourse Particles. Benjamins, Amsterdam/Philadelphia, pp. 141-162.

Karttunen, Lauri 1977. Syntax and Semantics of Questions. Linguistics and Philosophy 1: 344.

Karttunen, Lauri \& Peters, Stanley. 1979. Conventional Implicature. In Ch.-U. Oh \& D. A. Dinneen, eds., Presupposition. Syntax and Semantics 11. Academic Press, New York, pp. 1-56.

Kratzer, Angelika. 1999. Beyond 'Oops' and 'Ouch'. How Descriptive and Expressive Meaning Interact. Paper presented at the Cornell Conference on Theories of Context Dependency, 26 March 1999.

Lohnstein, Horst. 2000. Satzmodus - kompositionell: Zur Parametrisierung der Modusphrase im Deutschen. Akademie Verlag, Berlin.

Matushansky, Ora. 2003. Going through a Phase. Ms., CNRS/Université Paris. http://mapage.noos.fr/matushan/Downloads/Going.pdf

Molnár, Anna. 2001. Ein möglicher Weg der Grammatikalisierung der Modalpartikel, wohl'. Eine Fallstudie. In Piroska Kocsány \& Anna Molnár, eds., Wort und (Kon)text. Lang, Frankfurt/M., pp. 131-149.

Munaro, Nicola \& Cecilia Poletto. 2004. Sentential Particles and Clause Typing in Veneto Dialects. This volume.

Potts, Christopher. 2002a. Expressive Contrast as Conventional Implicature. paper presented at NELS 33, MIT, Nov. 8-10 2002.

Potts, Christopher. 2002b. The Syntax and Semantics of as-parentheticals. Natural Language \& Linguistic Theory 20: 623-689.

Rizzi, Luigi. 1997. The Fine Structure of the Left Periphery. In Liliane Haegeman, ed., Elements of Grammar. Kluwer, Dordrecht, pp. 281-337.

Stalnaker, Robert C. 1978. Assertion. In Peter Cole, ed., Pragmatics. Academic Press, New York, pp. 315-332.

Stechow, Arnim von. 1991. Focussing and Backgrounding Operators. In Werner Abraham, ed., Discourse Particles. Benjamins, Amsterdam/Philadelphia, pp. 37-84.

Weydt, Harald. 1969. Abtönungspartikel. Die deutschen Modalwörter und ihre französischen Entsprechungen. Gehlen, Bad Homburg.

Zimmermann, Malte. 2004. Zum ,Wohl': Diskurspartikeln als Satztypmodifikatoren. In Linguistische Berichte 199: 1-35. 